\title{
Study on the Path Selection of Regional Development in Karst Mountainous Areas Based on Evaluation of Location Advantages-A Case of Panxian County, Guizhou
}

\author{
Qian FENG \\ School of Karst Science, Guizhou Normal University \\ State Engineering Technology Center of Karst Rock \\ Desertification Rehabilitation \\ Guiyang, China \\ E-mail:939268275@qq.com
}

\author{
Quan CHENG \\ School of Karst Science, Guizhou Normal University \\ The State Key Laboratory Incubation Base for Karst \\ Mountain Ecology Environment of Guizhou Province \\ Guiyang, China \\ E-mail: cnqu123@163.com
}

\author{
Zhong-fa ZHOU* \\ School of Karst Science, Guizhou Normal University \\ The State Key Laboratory Incubation Base for Karst \\ Mountain Ecology Environment of Guizhou Province \\ Guiyang, China \\ E-mail:fa6897@163.com \\ Yu-ting HOU \\ School of Karst Science, Guizhou Normal University \\ State Engineering Technology Center of Karst Rock \\ Desertification Rehabilitation \\ Guiyang, China \\ E-mail: 2497429674@qq.com
}

\begin{abstract}
Choosing the regional development path reasonable according to the local advantages, and use them to promote the regional economy development, play a positive role. Using the correlation method of SPSS to analyze the relationship between the economic development level and the location advantages in Panxian county, evaluating location advantages by the inverse distance weight interpolation method in GIS, clearing resource advantages in different regional, achieving this goals that eviate the problem about large population with relatively littly land and the trouble of development in Karst area, putting forward several paths to promote the harmonious development of economy in Panxian county. The results of the study showed that by the usage of quantitative evaluation, mathematical model and other methods to evaluate the social problems will make the path selection more scientific and reasonable. GIS technology will be more widely used in the field of solve the problems in Social Sciences.
\end{abstract}

Keywords-Karst mountain area; location advantages; economic development level; development path; GIS

\section{INTRODUCTION}

The development of economic aspects including natural resources, geographical location, traffic and other elements of the comprehensive advantages of resources was reflected by the county location advantages, sound and fast economic development goals was achieved by play the advantages of maximum benefit and reasonable selection the efficient development path.At present, the domestic scholars focus on the research of the location advantages, which mainly focuses on the analysis of regional advantages in different areas by using different evaluation methods, the evaluation methods commonly used include location Quotient, location superiority degree model, qualitative evaluation based on location theory,hardware advantages,software advantages and agglomeration effect advantages,research fields including industry,agriculture,logistics-industry,city development, investment environment and ect $[1,2,3]$.The research contents of regional development path mainly include the perspective of the main functional areas, based on empirical analysis, the development path of a specific industry research and innovation, mode selection, strategy discussion and path comparison[4,5,6].On the whole, the location advantages is the basic condition for the development.The study of the relationship between location advantages and economic development will help to understand the importance of location advantages. Evaluation of regional advantages, is conducive to the understanding of the various regional advantages and potential development, has important significance to put forward the effective, applicable, scientific and rational development path, to provide the industrial layout, development planning and policy recommendations of the relevant government departments.

The slow development of the local social economy, the people living in poverty due to there are more people and less land,fragile ecological environment and low land productivity in Karst mountain area. Panxian county has typical characteristics of Karst, economic development imbalance between towns, evaluation of regional advantages in Panxian county, choose appropriate development path will conducive to promoting the economic development of Panxian county, narrowing the gap between the development of the township.

\section{STUDY AREA}

Pan County,belong to Liupanshui City,the cool city in China,is located in the west gate of Guizhou.The combined part with Yunnan, Guizhou and Guangxi three provinces. The specific location between 104'17'46"E 
$-104^{\circ} 57^{\prime} 46^{\prime \prime} \mathrm{E}$ and $25^{\circ} 19^{\prime} 36^{\prime \prime} \mathrm{N}-26^{\circ} 17^{\prime} 36^{\prime \prime N}$, East Puan County, south of Xingyi City, Xuanwei City, Yunnan province to the west, Fuyuan County, north of Shuicheng County, has a unique location, traffic advantages. Town wins highway and $\mathrm{Bi}$ - water - Hing highway intersection, Long Kun fast rail and $\mathrm{Bi}$ - water - Hing fast rail meeting, it is very convenient from Panxian county north to Chengdu, Chongqing, South to Nanning, east to Guiyang, West to Kunming [7,8].Land area $4056 \mathrm{~km}^{2}$, accounting for $2.3 \%$ of the province's total land area. The county's original 39 townships, followed by a reduction of 27 townships. Panxian county's total population of 11.8 billion people. Climate optimum, winter without cold, summer without heat, the annual average temperature is $15.2^{\circ} \mathrm{C}$.

Panxian county is rich in mineral resources.Gold, silver, copper, iron, lead, zinc, mercury, gypsum, asbestos, marble, coal bed gas and so on are all distributed. With the largest coal reserves, excellent quality of coal, for the southern provinces of the crown. Territory of the heritage category, cultural history, intangible cultural heritage, hot springs health category, scenic areas, parks and resorts scenic spots, rich tourism resources, great potential of tourism development. Industry is a pillar industry to support the development and progress of the county economy, but the mode of development is not sustainable, ecological efficiency is not high.Response to the concept of green sustainable development in the new era,it is a necessary way that change the mode of production, the layout of the industry and sustainable development.

\section{BASIC DATA SOURCES AND COMPUTATIONAL METHOD}

\section{A. Basic Data Sources}

Basic research data of this paper include of Pan county: (1) Geographic information basic data of Panxian county, the Development Zone, mineral resources distribution and tourism resources distribution;(2) GDP and total population data; (3) Rive distance and traffic distance from surrounding cities and counties to city center. Support materials and data from statistical yearbook,statistical bulletin of the national economic and social development in 2011-2015 about Pan county and relevant information provided by the government of Panxian county.

\section{B. Calculation Method}

\section{1) Correlation Analysis}

Correlation analysis is quantitative analysis method, was used to deal with the sample data, to study the correlation between the two variables and the linear correlation degree. There is completely related, not completely related and not related according to the degree of correlation. When the dependent variable increases with the increase or decreases with the decrease of the value of the argument, it is called a positive correlation, contrary to negative correlation, coefficient ranges from -1 to 1[9]. The common correlation coefficient has Pearson correlation coefficient, Kendall correlation coefficient and Spielman rank correlation coefficient, the Pearson correlation coefficient is used commonly in practice.

Calculation of correlation coefficient of Pearson:

$$
r_{x y}=\frac{\sum_{i=1}^{n}\left(x_{i}-\bar{x}\right)\left(y_{i}-\bar{y}\right)}{\sqrt{\sum_{i=1}^{n}\left(x_{i}-\bar{x}\right)^{2}} \sqrt{\sum_{i=1}^{n}\left(y_{i}-\bar{y}\right)^{2}}}
$$

In the formula, mean values of $\overline{\mathrm{X}}$ and $\overline{\mathrm{y}}$ for the two elements. $-1<=$ rxy $<=1$, positive correlation was expressed greater than 0 , negative correlation was expressed less than 0 . The absolute value of $r_{x y}$ is more close to 1 , and the relationship between the two elements is more closely; close to 0 , the two elements is not close.

Calculation of correlation coefficient of Kendall rank:

A method of multi level variables related to the degree of Kendall rank correlation coefficient, is non parametric statistics, a measure of the degree of correlation between two ordered variables or two rank variables, the influence of rank same point is considered. Structural statistics by the number (U) and inconsistent pair number (V) are calculated by using the rank data of variable.

$$
r=\frac{2(U-V)}{n(n-1)}
$$

Calculation of correlation coefficient of Spearman rank (rank):

Rank correlation coefficient, also known as rank correlation coefficient or order correlation coefficient, the distribution of the original variable is not required, it is a non parametric statistical method, wide range of application. A statistic by the data sequence ranking of the two elements of the sample values according to the size and the actual data was replaced accoding the precedence of factor sample value[10].

$$
r_{x y}^{\prime}=1-\frac{6 \sum_{i=1}^{n} d_{i}{ }^{2}}{n\left(n^{2}-1\right)}
$$

In the formula, di represents the difference between the values of each pair $(x, y)$, and the number of $n$ is the number of observations.

2) Inverse distance weighted spatial interpolation method (IDW)

Inverse distance weighted spatial interpolation method is a moving average weighted interpolation method that take distance as the weight, which is used to generate regular grid data according to discrete points[11]. The premise of using the spatial interpolation method is the characteristics of non uniform spatial distribution among the elements, the weight decreases with the increase of the distance between the sampling point and the interpolation point. The closer the interpolation points, the greater the weight of the sampling points[12]. The formula is as follows:

$$
Z_{(S 0)}=\sum_{i=1}^{N} \lambda_{i} Z_{(S i)}
$$

In the formula, $\mathrm{Z}$ ( $\mathrm{s} 0$ ) is to be estimated at the point of $\mathrm{S} 0, \mathrm{~N}$ to predict the number of points around the point to 
be used in the calculation process, $\lambda i$ for each known point of the weight, the value decreases with the increase of the distance between the sample and the prediction point, $\mathrm{Z}$ (si) for the measured value of known points obtained at $\mathrm{Si}$.

The calculation formula for determining the weight is:

$$
\lambda_{i}=\frac{1 / d_{i}^{k}}{\sum_{i=0}^{n} 1 / d_{i}^{k}}
$$

In the formula, $\mathrm{Di}$ is the distance between the point to be estimated and the known point, and $\mathrm{K}$ is the power exponent.

\section{RESULT OF ANALYSIS AND EVALUATION}

\section{A. Correlation Analysis Based on SPSS}

To analyze the level of Panxian county economic develop- ment and regional advantages use spss22.0 software, to explore the coupling relationship between the two. The economic development level and the location advantages of the evaluation value correlation into the SPSS and operation of two variable, available in TableI.

TABLE I. CORRELATION COEFFICIENT OF PEARSON

\begin{tabular}{|c|c|c|c|}
\hline & & $\begin{array}{c}\begin{array}{c}\text { Economic } \\
\text { development } \\
\text { level }\end{array} \\
\end{array}$ & $\begin{array}{c}\text { location } \\
\text { advantages }\end{array}$ \\
\hline \multirow{3}{*}{$\begin{array}{l}\text { Comprehensive } \\
\text { evaluation of } \\
\text { the level of } \\
\text { economic } \\
\text { development }\end{array}$} & $\begin{array}{c}\text { Pearson } \\
\text { correlation }\end{array}$ & 1 & $.704^{* *}$ \\
\hline & $\begin{array}{c}\text { Significant } \\
\text { (two tailed) }\end{array}$ & & .000 \\
\hline & $N$ & 27 & 27 \\
\hline \multirow{3}{*}{$\begin{array}{c}\text { Location } \\
\text { advantages }\end{array}$} & $\begin{array}{c}\text { Pearson } \\
\text { correlation }\end{array}$ & $.704^{* *}$ & 1 \\
\hline & $\begin{array}{l}\text { Significant } \\
\text { (two tailed) }\end{array}$ & .000 & \\
\hline & $N$ & 27 & 27 \\
\hline
\end{tabular}

**. Significant correlation was more than 0.01 (two tailed).

Kendall correlation coefficient and Spielman rank correlation coefficient were used to verify the results of Pearson correlation coefficient, in TableII.
TABLE II. KENDALL,SPEARMAN CORRELATION COEFFICIENT

\begin{tabular}{|c|c|c|c|c|}
\hline & & & $\begin{array}{c}\text { Economic } \\
\text { developm- } \\
\text { ent level }\end{array}$ & $\begin{array}{c}\text { Location } \\
\text { advan- } \\
\text { tages }\end{array}$ \\
\hline \multirow{6}{*}{$\begin{array}{c}\text { Kendall } \\
\text { 'taub }\end{array}$} & \multirow{3}{*}{$\begin{array}{c}\text { Economic } \\
\text { developme- } \\
\text { nt level }\end{array}$} & $\begin{array}{c}\text { Correlation } \\
\text { Coefficent }\end{array}$ & 1.000 & $.520^{* *}$ \\
\hline & & $\begin{array}{c}\text { Significant } \\
\text { (twotailed) }\end{array}$ & - & .002 \\
\hline & & $N$ & 27 & 27 \\
\hline & \multirow{3}{*}{$\begin{array}{c}\text { Location } \\
\text { advantages }\end{array}$} & $\begin{array}{c}\text { Correlation } \\
\text { Coefficent }\end{array}$ & $.520^{* *}$ & 1.000 \\
\hline & & $\begin{array}{c}\text { Significant } \\
\text { (twotailed) }\end{array}$ & .002 & . \\
\hline & & $N$ & 27 & 27 \\
\hline \multirow{6}{*}{$\begin{array}{l}\text { Spearma } \\
\text { n'rho }\end{array}$} & \multirow{3}{*}{$\begin{array}{c}\text { Economic } \\
\text { development } \\
\text { level }\end{array}$} & $\begin{array}{c}\text { Correlation } \\
\text { Coefficent }\end{array}$ & 1.000 & $.578^{* *}$ \\
\hline & & $\begin{array}{l}\text { Significant } \\
\text { (twotailed) }\end{array}$ & . & .002 \\
\hline & & $N$ & 27 & 27 \\
\hline & \multirow{3}{*}{$\begin{array}{c}\text { Location } \\
\text { advantages }\end{array}$} & $\begin{array}{c}\text { Correlation } \\
\text { Coefficent }\end{array}$ & $.578^{* *}$ & 1.000 \\
\hline & & $\begin{array}{c}\text { Significant } \\
\text { (twotailed) }\end{array}$ & .002 & . \\
\hline & & $N$ & 27 & 27 \\
\hline
\end{tabular}

**. Significant correlation was more than 0.01 (two tailed).

According to TABLEI, the correlation coefficient of Panxian county's economic development level and location advantages is 0.704 ,conspicuousness less than 0.05 , through the significance test.It shows that the level of economic development has a significant positive correlation with the advantages of location, that is, the area with good location advantages is the same or close to the region with high level of economic development. According to the results in TABLEII, Kendall correlation coefficient was 0.520 , Spielman correlation coefficient was 0.578 . It shows that the conclusion of the three different operation methods is consistent. The level of economic development has a significant positive correlation with the location advantages in Panxian county, close relationship between the two.

\section{B. The Evaluation of Location Advantages}

Consider the actual situation of Panxian county location advantages.First,calculation of the drive distance of various towns in Panxian county city to center city near by position ( 2 hours drive away), pick up economic data of the surrounding cities in 2015.According to the GDP of neighboring cities and counties in 2015, determine the evaluation coefficient $\beta$ of external location advantages; Secondly,evaluate the internal and external location advantages in township on the basis of classification criteria of location advantages;Finally, overall merit the External and internal location advantages. The final results concerning location advantages of Panxian county township are divided into smaller advantages, the advantages of general, the larger, greatest advantages of the 4 interval(TABLEIII). Analysis of the economic development situation and location advantages of the township in Panxian county, available in TABLEIV.

Using arcgis 10.1 to analyze the spatial interpolation of the evaluation value of the location advantages of Panxian county,a conclusion of the distribution of location advantages in Panxian county(Figure1). 
TANLEIII.THE EVALUATION RESULTS OF LOCATION ADVANTAGES IN PANXIAN COUNTY

\begin{tabular}{|c|c|c|}
\hline $\begin{array}{c}\text { Location } \\
\text { superiority } \\
\text { rank }\end{array}$ & Name of village and town & $\begin{array}{c}\text { Proportiy } \\
\text { of } \\
\text { Township }\end{array}$ \\
\hline Greatest & The street of HongGuo, HanLin, YiZi and & $15 \%$ \\
\hline LiangHe & The street of ShengJin and LiuGuan & $7 \%$ \\
\hline General & $\begin{array}{c}\text { The village of Pingdi, JiuYing and } \\
\text { PuTian.The town of JiChangPing, } \\
\text { PanGuan, YingWu, ShuangFeng, DanXia, } \\
\text { ShiQiao, XiangShui and BaoTian }\end{array}$ & $41 \%$ \\
\hline Smaller & $\begin{array}{c}\text { The village of PuGu, YuNi, BaoJi and } \\
\text { YangChang. The town of WuMeng, } \\
\text { BaiGuo, ZuHai, MinZu, DaShan and } \\
\text { XinMin }\end{array}$ & $37 \%$ \\
\hline \multicolumn{2}{|c}{} \\
\hline
\end{tabular}

TABLEIVTHE COMPREHENSIVE EVALUATION RESULTS OF ECONOMIC DEVELOPMENT LEVEL AND LOCATION ADVANTAGES OF EVERY TOWN IN PANXIAN COUNTY

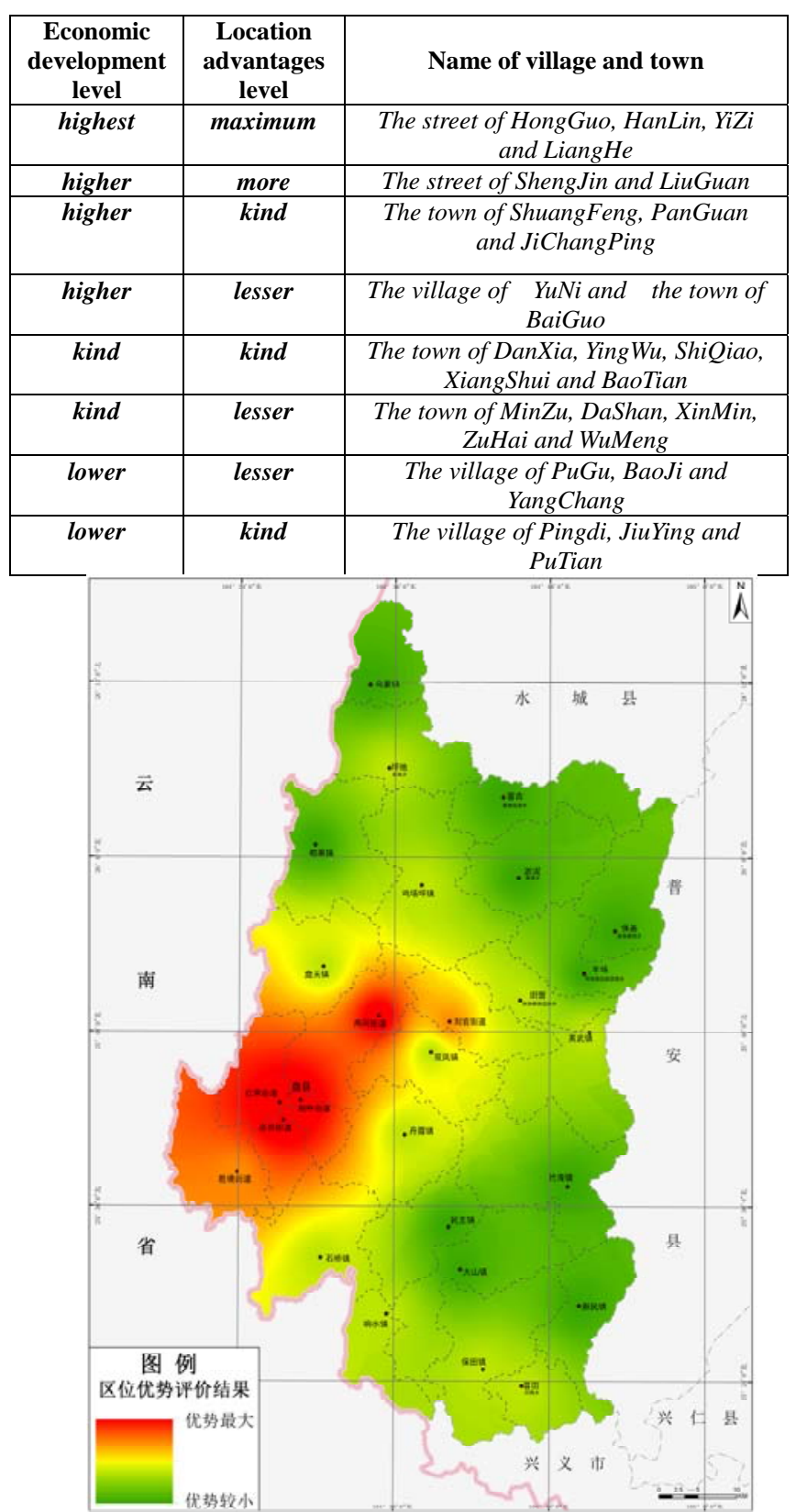

Figure1. IDW spatial interpolation of location advantages evaluation in Panxian county
Evaluation results of IDW spatial interpolation based on the location advantages of Panxian county, location distribution take the street of HongGuo, HanLin, YiZi and LiangHe as the biggest center and reduce to the north, the northeast, the eastern and southern of the county. The location advantages is smaller of the small town in northeast, southeast and north. Draw a comprehensive conclusion combined with the chart is greatest and larger of location advantages accounted for $22 \%$ in Panxian county, in general accounted for $63 \%$, overall location has a good advantages in Panxian county. But the economic development level and regional advantages are not the same.

\section{Comprehensive Evaluation}

Development zone is clear,there is priority development zone, key development area and restricted development area in Panxian county. 5 regions are priority development areas, each of the 6 with the key and the restricted development zone. The influence of Panxian county traffic artery is evaluated, all towns are affected by the traffic arteries. The influence degree of traffic trunk line is divided into the biggest, bigger, general and weak. The degree of influence is related to the distribution of rural traffic trunk lines. Good traffic conditions in Panxian county, traffic cross will lead Panxian county into the era of rapid development.

Abundant resources in Panxian county and affect the regional industrial layout, planning and development, and the level of economic development. We should make full use of the greatest and largest characteristic of location advantages in the street of HongGuo,HanLin.play the development of energy, radiation and auxiliary the function of the town center.Take effective measures to develop the town of the advantages kind, combined with other favorable conditions to promote the development and progress of township economy. The towns with a smaller location advantages, could be combined with the actual conditions and the potential development of resource,rational distribution industry, to promote the coordinated development of the county economy and reduce the gap of the regional development.

For solve the problem of low carrying capacity of resources and environment and ecological environment is fragile in the course of development. The regional development path must implementation concept about the ecological priority, green development. A breakthrough point of the ecological industry and high-end, Big health industry and the development of the tourism,by the construction of ecological, green production system to achieve.Go to the road of ecology, green, characteristic development as modern industrial system, high efficiency agriculture industry in modern mountain area, third industry represented by the modern service industry of tourism, electronic commerce development and modern logistics industry. Highlight the key development path, focus on other development path of the auxiliary benefits, cross fusion and push the economic development county. 


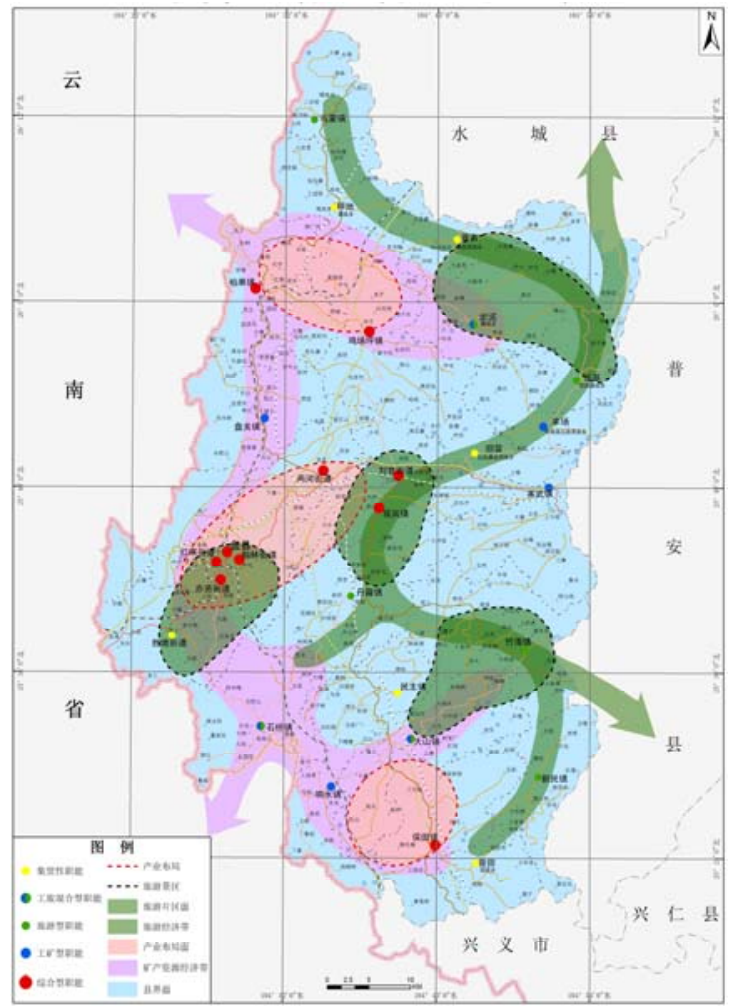

Figure 2. Layout of the comprehensive development of Panxian county

\section{CONCLUSION}

The rank correlation coefficient of Pearson,Kendall and Spielman analysis results show that the level of economic development has a significant positive correlation with the location advantages and close relationship in Panxian county, and overall location advantages is good. Location advantages has positive effect on economic development, the area with the advantages of location will have more opportunities for development when other development conditions are the same. The results by IDW spatial interpolation method show that the characteristic of location advantages presents one of the biggest centers and the situation is reduced, the number of villages and towns with good location advantages is small.Different development paths are selected according as different location advantages. Give full play to the role of location advantages,implementation of "going out" and "bringing in",consider other conditions of development, adjust the industrial structure, accelerate the pace of economic development.For the characteristics of the location advantages is not obvious, take into account the factors of resource advantages and policy oriented to chose development path. The location advantages is the basic condition that affects the level of regional economic development, is also one of the factors that should be considered in the choice of development path.

It is scientific and reasonable that IDW spatial interpolation and correlation analysis method are used to evaluate the correlation between the two variables and the law of the single factor.The distribution characteristics of elements in space and time are clearly reflected. Reflects the wide use of GIS in the field of social science, The decision more scientific and reasonable by using quantitative evaluation, mathematical methods, evaluation models and other methods to evaluate social problems.

\section{ACKNOWLEDGMENTS}

In this paper, the research was sponsored by the National Natural Science Fund regional project of Stu dy on the coupling mechanism of eco assets and reg ional poverty in Karst Rocky Desertification Area ( 41661088); The major application foundation researchp roject of Guizhou Province(Guizhou S\&T Contract J Z 2014-200201); The soft science research project of Development and Reform Commission of Pan Cou -nty,Guizhou Province(20151231).

Thanks to the guidance and support from the Dev elopment and Reform Commission of Pan County.

\section{REFERENCES}

[1] $\mathrm{Xu}$ MingDe,Wang Seng. Analysis of location advantages degr ee based on road and town[J]. World Regional Studies,2009,0 4:91-99.

[2] Xie Baopeng,Zhu Daolin,Chen Ying,et al.Mode selection for ural residential land consolidation based on analysis of locatio $\mathrm{n}$ condition[J].Transactions of the Chinese Society of Agricult ural Engineering,2014,01:219-227.

[3] Wang Wenjiao, Chen Zhihong.Research on the dynamic adjust ment of China's foreign investment location advantages-Based on the analysis of spatial and temporal data based on geogr aphical weighted regression[J].International trade issues,2014,0 6:112-122.

[4] Hu Jing.Study on Western Hubel's Regional Development Stra te-gies and Implementation-A Tourism-LED and Regionally C oll-aborative Development Approach[D].HuaZhong Agricultural University,2010.

[5] Pu YanXiang,Song LiHua,Qi JianLing,Yang JingHong.The path of opening to the outside world and the development of $\mathrm{Re}$ gional Economy: a comparison between the Yangtze River De lta and the Pearl River Delta[J]. Economic Research Guide,20 16,04:48-51.

[6] Tang WeiGuo. On the original innovation of the path of the re-gion spanning development[J].Jounal of Yangzhou Universit y (Humanities\&Social Sciences) ,2006,03:9-14.

[7] Reporter.Cheng ShiZhong.The era of rapid development by tra ffi-c cross to lead Panxian county into[N].Guizhou Daily,2009 - 10-16008.

[8] Panxian county strong breakthrough traffic bottlenecks to achi eve rapid development[N].Guizhou Daily,2010-12-28005.

[9] Zhang JinYan,Yang FuTing,Jiang ZhongLun,Li Chen.Investigati on on poverty problem in resource rich areas -- a case study of Panxian in Guizhou Province[J].Eco economic review,20 11,00:153-168

[10] WuSong,PanFaMing.SPSS Statistical analysis[Z].Bei Jing:Tsing hua University Press,2014.

[11] Li XiaoHui,Yuan Feng,Jia Cai,Zhang Mingming,Zhou TaoFa.A comparative study of S-A multi fractal filtering inverse dista nce weighted and Kriging interpolation based on[J].Science of Surveying and Mapping,2012,03:87-89.

[12] Tang Guoan,Yang Xin.The experiment course of ArcGIS geog raphic information system spatial analysis(the second edition)[ Z].Bei Jing:Science Press,2006.

[13] LiChen,Deng Wengsheng.Analysis on Economic Level in Zho ngyuan Urban Agglomeration Based on GIS[J]. Resource Dev elopment\&Market,2008,11:995-996. 